\title{
ANÁLISE DOS PARTIDOS POLÍTICOS BRASILEIROS SOBRE SEUS PROGRAMAS DE INTEGRIDADE
}

\section{ANALYSES OF BRAZILIAN POLITICAL PARTIES ON THEIR INTEGRITY PROGRAMS}

\author{
Gustavo Santana Silva*
}

\begin{abstract}
RESUMO
Os partidos políticos são aglomerações de cidadãos com visões ideológicas comuns no intuito de contribuir para a construção de uma sociedade e a organização do Estado. Os partidos são um importante meio de participação popular na determinação da política institucional. No entanto, a percepção da população (em geral) dos partidos políticos são ruins, muitas vezes atrelados ao patrimonialismo e autoritarismo brasileiro. A percepção passa pela ideia de que os partidos são verdadeiramente "currais", onde seus "donos" fazem do partido a extensão de seu patrimônio pessoal, com nítida violação dos ideais republicanos e escolhas políticas nada democráticas. O presente artigo tem por objetivo verificar ou observar até quando vai tal percepção é verdadeira nos documentos oficiais dos partidos no tema da integridade.
\end{abstract}

Palavras chaves: Compliance Público. Partidos Políticos. Integridade.

\begin{abstract}
Political parties are agglomerations of citizens with common ideological views in order to contribute to the construction of a society and the organization of the state. The parties are an important means of popular participation in determining institutional politics. However, the perception of political parties by the population (in general) is bad, often linked to Brazilian patrimonialism and authoritarianism. The perception is that the parties are truly "corrals", where their "owners" turn the party into an extension of their personal patrimony, with a clear violation of the republican ideals and undemocratic political choices. The present article aims to verify or observe how far this perception is true in the parties official documents on the subjects of integrity.
\end{abstract}

Keywords: Public compliance. Political parties. Integrity

Artigo submetido em 12 de setembro de 2021 e aprovado em 14 de fevereiro de 2022.

* Graduado em Direito pela Universidade Estácio de Sá, Fortaleza, Ceará, Brasil. Pós graduado em Compliance e Integridade Corporativa pela Pontifícia Universidade Católica de Minas Gerais, Brasília, Distrito Federal, Brasil. E-mail: gs_silva@ymail.com. 


\section{INTRODUÇÃO}

No cenário nacional, totalizam 33 (trinta e três) partidos registrados no Tribunal Superior Eleitoral ${ }^{1}$, com 24 (vinte quatro) partidos com representação na Câmara dos Deputados e 14 (quatorze) no Senado Federal ${ }^{2}$ - Congresso Nacional.

Tendo em vista que os partidos políticos, no mundo ideal, têm o interesse em bem conduzir os negócios públicos para o aprimoramento da democracia e das instituições. No Brasil, no entanto, a falta de interesse pelo temática da integridade é bem demonstrada no Ranking da Transparência Partidária ${ }^{3}$ ( $1^{\circ}$ ed, 2018) pelo Movimento da Transparência Partidária. A falta de interesse perpassa e é bem estudada pela literatura (sociologia e etc) no que toca à temática do patrimonialismo e autoritarismo brasileiro, no qual este trabalho não tem como escopo analisar as causas.

Após a decisão do Supremo Tribunal Federal de proibir a doação privada aos partidos, a minirreforma eleitoral introduziu o Fundo eleitoral ou partidário (para os partidos) e o Fundo para campanhas.

Para fins de elucidação os partidos políticos receberam pelo Fundo Especial de Assistência Financeira aos Partidos Políticos, vulgo fundão partidário, foi de R\$ 895.093.314,00 como Dotação orçamentária e R\$ 67.045.038,45 como Multas em 2021 ${ }^{4}$; e para o Fundo Especial de Financiamento de Campanha - FEFC, segundo o Tribunal Superior Eleitoral, para a eleição geral de 2020 o valor do FEFC foi de R \$2.034.954.824.

Para o Fundo de assistência aos partidos para 2022 fala-se em torno de R \$5 bi.

Podemos concluir que é muito dinheiro que os partidos recebem e administram, sem contudo, qualquer controle social ou transparência, no qual pode contribuir para reforçar a percepção popular da ideia de que os partidos são verdadeiramente "currais", onde seus "donos" fazem do partido a extensão de seu patrimônio pessoal, com nítida violação dos ideais republicanos e escolhas políticas nada democráticas.

Portanto, o presente trabalho tem como parâmetros gerais analisar e descrever se os partidos vão além do determinado pela legislação ao verificar se praticam a transparência ativa partidária com o dinheiro público e como os partidos se organizam e se estruturam na condução do tema da integridade, a partir de informações e documentos disponibilizados e retirados nos endereços eletrônicos dos próprios partidos.

Por fim, não se pretende de forma alguma demonizar ou dar justificativa para depreciar os partidos políticos, a realidade se justifica por si só, mas uma tentativa de ajudar aos partidos a melhorar a condução política do país ao reforçar a integridade como objeto fundamental na construção da confiança pública sobre o sistema partidário.

\subsection{Metodologia}

Primeiramente a presente pesquisa tem como analise a seguinte estrutura:

- Análise será na ordem decrescente com mais bancada para quem tem menos deputados(as) ${ }^{5}$;

\footnotetext{
${ }^{1}$ https://www.tse.jus.br/partidos/partidos-politicos/registrados-no-tse. Acesso em Agosto de 2021.

${ }^{2}$ Bancada dos partido no Senado Federal: https://www25.senado.leg.br/web/senadores/em-exercicio/-/e/porpartido\#CIDADANIA. Acesso em Agosto de 2021

${ }^{3}$ https://uploads.strikinglycdn.com/files/54eabca2-0530-457d-948d-d17213d13b38/ranking_FINAL.pdf

${ }^{4}$ Funhttps://www.tse.jus.br/partidos/contas-partidarias/fundo-partidario-1

5 Bancada dos partidos na Câmara dos Deputados: https://www.camara.leg.br/Internet/Deputado/bancada.asp. Acesso em Agosto de 2021
} 
- Análise dos Estatutos e/ou Código de Ética e Conduta dos partidos com representação na Câmara dos Deputados;

- Análise do programa de compliance dos partidos ou identificar funções ou estruturas de compliance nos estatutos ou códigos ou regulamentos disponíveis nos endereços eletrônicos;

- A representação foi analisada na $56^{\circ}$ Legislatura (2019 - 2023);

- Pesquisa exclusivamente documental, como a melhor forma encontrada de garantir a objetividade na análise;

- Todos os critérios devem ser acessíveis ao cidadão pelo endereço eletrônico do próprio do partido, preferencialmente na página inicial.

Critérios ou requisitos na análise dos documentos disponibilizados pelos partidos em seus endereços eletrônicos:

1. Suporte da alta administração;

2. Canal de denúncias - ouvidoria, etc;

3. Estrutura interna de compliance - Comitê de Ética, Fiscal, etc;

4. Prestação de contas.

Para os critérios serão estabelecidos o seguinte quadro de análise individual:

\begin{tabular}{|c|c|c|c|c|}
\hline REQUISITOS & $\begin{array}{c}\text { Não } \\
\text { atendeu }\end{array}$ & $\begin{array}{c}\text { Parcialmente, } \\
\text { porém não } \\
\text { satisfatório. }\end{array}$ & $\begin{array}{c}\text { Parcialmente, } \\
\text { porém } \\
\text { satisfatório }\end{array}$ & Integralmente \\
\hline Suporte & & & & \\
\hline $\begin{array}{c}\text { Canal de } \\
\text { denúncias }\end{array}$ & & & & \\
\hline Estrutura interna & & & & \\
\hline $\begin{array}{c}\text { Prestação de } \\
\text { contas }\end{array}$ & & & & \\
\hline
\end{tabular}

$\mathrm{Na}$ análise do critério "Suporte da alta administração" será analisado o acesso ou sua facilidade ao Estatuto e do Código de Ética e Conduta ou outras regras normativas internas, haja vista que a presente análise é documental, tendo a difícil análise desse critério na prática.

Para este requisito, parte-se do pressuposto que o conteúdo nos endereços eletrônicos é de conhecimento da alta administração, então a existência ou acesso do Estatuto e do Código de Ética e Conduta será marcado como "Integralmente". A existência ou acesso do Estatuto ou do Código será marcado como "Parcialmente, porém satisfatório".

Manifesto ou Programa Partidário não tem o condão de substituir o Código de Ética e Conduta, então serão considerados equivalentes, todavia não serão considerados para a avaliação.

Todos os critérios devem ser acessíveis ao cidadão pelo sítio eletrônico próprio do partido, caso não exista ou não seja acessível será marcado como "Não atendeu" o critério de suporte da alta administração.

No "Canal de denúncias" será marcado: 
- "Integralmente" a existência de uma ouvidoria;

- "Parcialmente, porém satisfatório" a existência de uma ouvidoria, mas não é facilmente acessível;

- "Parcialmente, porém não satisfatório" a existência de um "Fale Conosco" no sítio eletrônico ou tem previsão no Estatuto ou outro contato com o partido, ou seja, não está claro onde se deve direcionar a denúncia;

- "Não atendeu" inexiste canal de denúncia ou não é acessível ao cidadão. Na estrutura interna:

- "Integralmente" existência de uma estrutura de compliance como um departamento ou setor;

- "Parcialmente, porém satisfatório" existência de uma Comissão de ética ou fiscal;

- "Parcialmente, porém não satisfatório" existe uma Comissão de ética ou fiscal, mas sua previsão é falha;

- "Não atendeu" inexiste qualquer estrutura ou não é acessível ao cidadão.

No último critério "Prestação de contas" será analisada a acessibilidade das contas partidárias, ou seja, a transparência ativa partidária propriamente dita, bem como a existência de regras orçamentárias no Estatuto ou em resoluções do partido.

Os requisitos serão analisados de maneira individual.

\section{ESTADO DEMOCRÁTICO DE DIREITO E PARTIDOS POLÍTICOS}

\subsection{Partidos Políticos}

Historicamente os partidos surgem precipuamente no século XIX, na Europa e nos Estados Unidos.

Norberto Bobbio em seu livro Dicionário de Política (11ª ed, 1998) traz brilhantemente as etapas dos partidos que são:

a) "Partidos dos notáveis" - primeira metade do século XIX;

b) Partidos de organização de massa - segunda metade do século XIX;

c) Partidos eleitoral de massa.

A etapa inicial dos partidos como "partido dos notáveis", era uma estrutura organizativa relativamente simples que tinha como objetivo principal executar as normas previstas em lei para a eleição para o Parlamento e recolher votos para um determinado candidato. Para completar estes partidos "funcionavam quase exclusivamente durante os períodos eleitorais e eram liderados por notáveis locais, aristocratas ou burgueses de alta sociedade, que proviam à escolha dos candidatos e ao financiamento da atividade eleitoral." (BOBBIO, 1998, p. 899)

$\mathrm{Na}$ etapa seguinte, os partidos têm uma mudança substancial com o surgimento dos partidos socialistas. O partido é "um séquito de massa, uma organização difusa, e estável com um corpo de funcionários pagos especialmente para desenvolver uma atividade política e um programa político-sistemático." (BOBBIO, 1998, p. 900).

Assim, nos partidos de organização de massa ou "partido de aparelho" as pessoas qualificadas ou "notáveis" se dedicavam à educação e propaganda do partido em tempo integral, os quais sustentavam os partidos financeiramente, ou seja, se dedicavam no proselitismo 
político, enquanto os trabalhadores tinham o título de honra no partido, em razão dos trabalhadores não terem tempo de dedicação para a política.

Bobbio (1998, p. 902) prossegue ao definir uma característica desses partidos de aparelho "como a alta participação das bases na vida do partido, a contínua ação de educação moral e intelectual das massas, a precisão do programa político e o apelo à transformação da sociedade.", aqui está a origem dos "partidos modernos", no entanto estes partidos foram perdendo esta característica para os partidos eleitoral de massa.

Por vários motivos, políticos e sociais, os partidos de organizações de massa se transformam em partidos eleitoral de massa ou "partido pega tudo".

Nos partidos eleitoral de massa tem por objetivo "procuram conquistar a confiança dos estratos mais diversos da população, propondo em plataformas amplas e flexíveis, além de suficientemente vagas, a satisfação do maior número de pedidos e a solução dos mais diversos problemas sociais." (BOBBIO, 1998, pg 902). Aqui os partidos adquirem uma conotação mais eleitoral.

Assim, a função do partido pode variar conforme o tempo, a época ou o contexto histórico, ou seja,

[...] podemos afirmar que se o fenômeno "partido" como configuração organizativa e como conjunto de funções por ele desenvolvidas mostra, em termos gerais, uma tipicidade própria, do ponto de vista concreto e analítico se apresenta de modo muito diferente pelo que, para captar sua especificidade e a relevância atual num dado sistema político, é necessário vê-lo inserido na estrutura econômico-social e política de um determinado país, num bem definido momento histórico. (BOBBIO, 1998, p. 905)

Atualmente podemos encontrar partidos de organização de massas ou eleitoral de massa no cenário político brasileiro.

Diante da complexidade das relações políticas e das diversidades sociais, podemos concluir que os partidos ainda possuem um caráter organizativo extremamente complexo para a conquista do poder político (benefícios pessoais para os líderes ou por ideal ou por ambos).

No cenário político brasileiro a percepção popular em geral dos partidos políticos é de conquista do poder para o benefício pessoal do(s) líder(es), ou seja, no Brasil isto não é bem visto.

\subsection{Estado Democrático de Direito}

O Estado de Direito pode ser simplificado como o Estado regido/guiado pela lei.

A Constituição Federal determina em seu artigo $5^{\circ}$, XIV (“é assegurado a todos o acesso à informação e resguardado o sigilo da fonte, quando necessário ao exercício profissional;"). Para o estudo dos direitos humanos a doutrina classifica os direitos humanos em vertical, aquele aplicado contra o Estado, e os direitos humanos horizontais, aquele onde se pode aplicar contra o particular. Tanto de se abster, como obrigação de fazer.

O Estado democrático pode ser simplificado como participação/soberania popular. Como determina a Constituição Federal em seu artigo $14, \S 3^{\circ}, \mathrm{V}$, a filiação partidária é obrigatória, portanto, o partido tem o monopólio da representação política no Brasil e como todo monopólio tem suas ineficiências, a falta de transparência tende a ser uma delas. Para alguns este monopólio restringe a participação de estratos mais diversos da população.

Para Norberto Bobbio (1998, p. 905) "[...] a possibilidade de os partidos serem instrumento de democracia está dependente do controle direto e da participação das massas". De forma complementar, esse tal controle não é possível sem a transparência, sem os partidos darem publicidade das contas partidárias ou de como estão conduzindo o tema da integridade em seus partidos. 
A partir das mudanças das estruturas sociais atuais que vem classificando a transparência como exercício e expressão da cidadania contemporânea, os partidos irão se adequar às novas exigências como já fizeram em diversos tempos históricos antes diante de demandas políticas, econômicas e sociais, mas é necessário um movimento político-social nesse sentido.

\section{ANÁLISE DOS PARTIDOS POLÍTICOS}

\subsection{Partido Social Liberal - PSL}

Bancada com 53 deputados(as).

Bancada com 1 senadora.

Endereço eletrônico: https://psl.org.br/

$\mathrm{Na}$ abertura já podemos observar a palavra "Compliance" (https://psl.org.br/compliance/). Pelo critério de que o conteúdo no sítio eletrônico é de conhecimento da alta administração, o PSL tem o suporte da alta administração. Podemos encontrar o Estatuto e outras normas de compliance no sítio eletrônico, mas não se encontra na página inicial. O partido possui Código de Ética e Conduta ${ }^{6}$.

O canal de denúncias (e-mail: ouvidoria@psl.org.br) é previsto na Resolução interna CEN 007/2020 e é acessível ou está disponível no seguinte endereço eletrônico: https://psl.org.br/compliance/.

Para o terceiro critério no Estatuto podemos encontrar o "Conselho de ética, fidelidade e disciplina partidária" nos artigos 108 e 109 (competência). Enquanto na Resolução interna CEN 007/2020 podemos observar a existência de um Departamento de Compliance na estrutura do partido. Na Resolução interna CEN 003/2020 se observa o Setor de Compliance no Diretório Nacional na figura do Compliance Officer (art. $7^{\circ}$ ).

No Estatuto podemos observar a existência de um Conselho Fiscal nos artigos $110 \mathrm{e}$ 111 (competência).

A estrutura partidária não pode ser encontrada facilmente, exceto os "Diretórios do PSL" que são os diretórios estaduais, após clicar na parte superior "Diretórios" na página inicial. Para o quarto critério, não foi encontrada nenhuma prestação de contas ou links para a justiça eleitoral. Não foram encontradas as contas do partido. Apesar da boa intenção do partido, a transparência ainda necessita melhorar.

$\mathrm{Na}$ Resolução interna 004/2020 podemos observar a iniciativa do partido em disciplinar as "boas práticas de gestão partidária, orientado pelas normas de Compliance, em todas as transações, contratações e negociações pelos órgãos partidários nacional, estaduais, municipais ou zonais."

Como noticiado pela mídia em geral, o referido partido junto ao partido DEMOCRATAS - DEM planejam uma fusão, então a referida análise poderá sofrer mudança.

\begin{tabular}{|c|c|c|c|c|}
\hline REQUISITOS & $\begin{array}{c}\text { Não } \\
\text { atendeu }\end{array}$ & $\begin{array}{c}\text { Parcialmente, } \\
\text { porém não } \\
\text { satisfatório. }\end{array}$ & $\begin{array}{c}\text { Parcialmente, } \\
\text { porém } \\
\text { satisfatório }\end{array}$ & Integralmente \\
\hline Suporte & & & & $\mathrm{X}$ \\
\hline
\end{tabular}

${ }^{6}$ https://psl.org.br/CodEtica/CodigoEtica.pdf 


\begin{tabular}{|c|c|c|c|c|}
\hline $\begin{array}{c}\text { Canal de } \\
\text { denúncias }\end{array}$ & & & $X$ & \\
\hline Estrutura interna & & & $X$ & \\
\hline $\begin{array}{c}\text { Prestação de } \\
\text { contas }\end{array}$ & $\mathrm{X}$ & & & \\
\hline
\end{tabular}

\subsection{Partido Dos Trabalhadores - PT}

Bancada com 53 deputados(as).

Bancada com 6 senadores.

Endereço eletrônico: https://www.pt.org.br/

No sítio eletrônico podemos encontrar facilmente o Estatuto do partido no final da página inicial. Podemos observar que o Estatuto é bem detalhado e extenso, chegando a ter 271 artigos. Não foi encontrado Código de Ética e Conduta na página inicial do partido, apesar de ser acessível o Manifesto principiológico do partido, tendo sua violação a medida disciplinar correspondente.

No segundo critério não foi encontrado o canal de denúncias, tanto no sítio eletrônico como em Resoluções do partido. No Estatuto se observa a existência da "Ouvidoria do Partido" (artigos 249 e 250).

No final da página se encontram as "Notas e Resoluções", porém não foram encontrados nenhuma resolução do partido, somente notas.

No Estatuto no Título VII - DA DISCIPLINA E DA FIDELIDADE PARTIDÁRIAS que compreende os artigos 217 ao 248, está nos artigos 217 ao 223 a previsão das Comissões de Ética e Disciplina. No final da página podemos encontrar facilmente a estrutura do partido, apesar de não encontrar outra estrutura de compliance, senão, somente a "Comissão de ética e disciplina".

No Estatuto podemos observar a existência de um Conselho Fiscal nos artigos 215 e 216.

Para o quarto critério, não foi encontrada nenhuma prestação de contas ou links para a justiça eleitoral. Não foram encontradas as contas do partido.

No entanto, se observa nos artigos 176 ao 216 a previsão das finanças e da contabilidade do partido. E nos artigos 260 ao 262 a previsão do TÍTULO XI DO PATRIMÔNIO DO PARTIDO.

\begin{tabular}{|c|c|r|r|r|}
\hline $\begin{array}{c}\text { REQUISI } \\
\text { TOS }\end{array}$ & $\begin{array}{r}\text { ão } \\
\text { atendeu }\end{array}$ & $\begin{array}{c}\text { Parcial } \\
\text { mente, porém } \\
\text { não } \\
\text { satisfatório. }\end{array}$ & $\begin{array}{c}\text { Parcia } \\
\text { lmente, } \\
\text { porém } \\
\text { satisfatório }\end{array}$ & $\begin{array}{c}\text { Integra } \\
\text { lmente }\end{array}$ \\
\hline Suporte & & $\mathrm{X}$ & & \\
\hline $\begin{array}{c}\text { Canal de } \\
\text { denúncias }\end{array}$ & & $\mathrm{X}$ & & \\
\hline $\begin{array}{c}\text { Estrutura } \\
\text { interna }\end{array}$ & & & & \\
\hline
\end{tabular}




\begin{tabular}{|r|r|l|l|l|}
\hline $\begin{array}{c}\text { Prestação } \\
\text { de contas }\end{array}$ & $\mathrm{X}$ & & & \\
\hline
\end{tabular}

\subsection{Partido Liberal - PI}

Bancada com 41 deputados(as).

Bancada com 4 senadores.

Endereço eletrônico: http://pl22.com.br/

Não foi encontrado o Estatuto, Código de Ética e Conduta, Resoluções, Canal de denúncias ou qualquer estrutura de compliance.

Não atende aos critérios estipulados.

\begin{tabular}{|c|r|r|r|l|}
\hline $\begin{array}{c}\text { REQUISI } \\
\text { TOS }\end{array}$ & $\begin{array}{r}\text { N } \\
\text { ato } \\
\text { atendeu }\end{array}$ & $\begin{array}{c}\text { Parcia } \\
\text { lmente, } \\
\text { porém não } \\
\text { satisfatório. }\end{array}$ & $\begin{array}{c}\text { Parcia } \\
\text { lmente, } \\
\text { porém } \\
\text { satisfatório }\end{array}$ & $\begin{array}{c}\text { Integr } \\
\text { almente }\end{array}$ \\
\hline Suporte & $\mathrm{X}$ & & & \\
\hline $\begin{array}{c}\text { Canal de } \\
\text { denúncias }\end{array}$ & $\mathrm{X}$ & & & \\
\hline $\begin{array}{c}\text { Estrutura } \\
\text { interna }\end{array}$ & $\mathrm{X}$ & & & \\
\hline $\begin{array}{c}\text { Prestação } \\
\text { de contas }\end{array}$ & $\mathrm{X}$ & & & \\
\hline
\end{tabular}

\subsection{Progressista - PP}

Bancada com 41 deputados(as).

Bancada de 7 senadores(as).

Endereço eletrônico: https://progressistas.org.br/

No sítio eletrônico podemos encontrar facilmente o Estatuto do partido no final da página inicial. Não foi encontrado Código de Ética e Conduta na página inicial do partido ou outras normas de compliance.

Não foi encontrado o canal de denúncias. O "Conselho de ética" é encontrado no artigo 82 a 84 do Estatuto, não foi encontrado outras estruturas internas de compliance. Para o quarto critério, não foi encontrada nenhuma prestação de contas ou links para a justiça eleitoral. Não foram encontradas as contas do partido pelo sítio eletrônico.

\begin{tabular}{|c|c|c|c|c|}
\hline $\begin{array}{l}\text { REQUISI } \\
\text { TOS }\end{array}$ & $\begin{array}{l}\mathrm{N} \\
\text { ão } \\
\text { atendeu }\end{array}$ & $\begin{array}{r}\text { Parcial } \\
\text { mente, porém } \\
\text { não } \\
\text { satisfatório. }\end{array}$ & $\begin{array}{l}\text { Parcia } \\
\text { lmente, } \\
\text { porém } \\
\text { satisfatório }\end{array}$ & $\begin{array}{l}\text { Integr } \\
\text { almente }\end{array}$ \\
\hline
\end{tabular}




\begin{tabular}{|r|r|r|r|l|}
\hline Suporte & & & $\mathrm{X}$ & \\
\hline $\begin{array}{c}\text { Canal de } \\
\text { denúncias }\end{array}$ & $\mathrm{X}$ & & & \\
\hline $\begin{array}{c}\text { Estrutura } \\
\text { interna }\end{array}$ & & $\mathrm{X}$ & & \\
\hline $\begin{array}{c}\text { Prestação } \\
\text { de contas }\end{array}$ & $\mathrm{X}$ & & & \\
\hline
\end{tabular}

\subsection{Partido Social Democrático - PSD}

Bancada com 35 deputados(as).

Bancada com 11 senadores.

Endereço eletrônico: https://psd.org.br/

No endereço eletrônico podemos encontrar facilmente o Estatuto do partido na parte superior da página inicial. Não foi encontrado Código de Ética e Conduta na página inicial do partido ou outras normas de compliance.

Não foi encontrado o canal de denúncias. O Conselho Fiscal e o Conselho de ética partidária são órgãos auxiliares do partido. Porém, à Executiva Nacional cabe "exercer a ação disciplinar artigo sobre todas as instâncias da administração partidária e sobre os filiados" (artigo 60, alínea f, do Estatuto). Ao Conselho de ética pelo artigo 75 cabe a função de emitir parecer quando convocado, ou seja, função consultiva.

A Resolução $n^{\circ}$ 56, da Comissão Executiva Nacional, de 16 de março de 2016, dispõe sobre as normas para arrecadação, aplicação e distribuição de recursos financeiros para as eleições de 2016.

Para o quarto critério, não foi encontrada nenhuma prestação de contas ou links para a justiça eleitoral. Não foram encontradas as contas do partido.

\begin{tabular}{|c|r|r|r|l|}
\hline $\begin{array}{c}\text { REQUISI } \\
\text { TOS }\end{array}$ & $\begin{array}{r}\mathrm{N} \\
\text { ão } \\
\text { atendeu }\end{array}$ & $\begin{array}{r}\text { Parcia } \\
\text { lmente, } \\
\text { porém não } \\
\text { satisfatório. }\end{array}$ & $\begin{array}{r}\text { Parcial } \\
\text { mente, porém } \\
\text { satisfatório }\end{array}$ & $\begin{array}{c}\text { Integr } \\
\text { almente }\end{array}$ \\
\hline Suporte & $\mathrm{X}$ & & $\mathrm{X}$ & \\
\hline $\begin{array}{c}\text { Canal de } \\
\text { denúncias }\end{array}$ & & $\mathrm{X}$ & & \\
\hline $\begin{array}{c}\text { Estrutura } \\
\text { interna }\end{array}$ & $\mathrm{X}$ & & & \\
\hline $\begin{array}{c}\text { Prestação } \\
\text { de contas }\end{array}$ & & & & \\
\hline
\end{tabular}

\subsection{Movimento Democrático Brasileiro - MDB}

Bancada de 33 deputados(as).

Bancada de 15 senadores(as). 
Endereço eletrônico: https://www.mdb.org.br/

No endereço eletrônico podemos encontrar facilmente o Estatuto do partido na parte superior da página inicial. O partido possui Código de Ética e Conduta ${ }^{7}$ que "dispõe sobre as Comissões de Ética e Disciplina, define os deveres éticos dos filiados e dos órgãos do Partido Do Movimento Democrático Brasileiro, as penalidades a que estão sujeitos e estabelece a normas do respectivo processo".

Não foi encontrado o canal de denúncias. Na página inicial foi encontrado o contato do Diretório Nacional (diretorionacional@mdb.org.br / (61) 3771-4200 / 3771-4201), no entanto, permanece vago onde poderia enviar a denúncia.

Se observa a existência das Comissões de Ética e Disciplina (artigo 45 a 47) e o Conselho Fiscal em um único artigo (artigo 53). Não foi encontrado demais normas partidárias que poderiam corroborar a existência de outras estruturas de compliance no partido.

No entanto, se destaca a RESOLUÇÃO N. ${ }^{\circ}$ 002/2020 - CORONAVÍRUS ${ }^{8}$ respondendo com agilidade ao novo risco decorrente da pandemia de COVID 19.

Para o quarto critério, não foi encontrada nenhuma prestação de contas ou links para a justiça eleitoral. Não foram encontradas as contas do partido, porém pode-se observar regras de contabilidade e prestação de contas das campanhas eleitorais nos artigos 114 a 119 do Estatuto.

\begin{tabular}{|c|c|r|r|r|}
\hline $\begin{array}{c}\text { REQUISI } \\
\text { TOS }\end{array}$ & $\begin{array}{r}\text { Parcial } \\
\text { atendeu }\end{array}$ & $\begin{array}{r}\text { Parcial } \\
\text { mente, porém } \\
\text { não } \\
\text { satisfatório. }\end{array}$ & $\begin{array}{c}\text { mente, porém } \\
\text { satisfatório }\end{array}$ & $\begin{array}{r}\text { Integr } \\
\text { almente }\end{array}$ \\
\hline Suporte & & $\mathrm{X}$ & & \\
\hline $\begin{array}{c}\text { Canal de } \\
\text { denúncias }\end{array}$ & & $\mathrm{X}$ & & \\
\hline $\begin{array}{c}\text { Estrutura } \\
\text { interna }\end{array}$ & & $\mathrm{X}$ & & \\
\hline $\begin{array}{c}\text { Prestação } \\
\text { de contas }\end{array}$ & $\mathrm{X}$ & & & \\
\hline
\end{tabular}

\subsection{Partido da Social Democracia Brasileira - PSDB}

Bancada de 33 deputados(as).

Bancada de 7 senadores(as).

Endereço eletrônico: https://www.psdb.org.br/

No endereço eletrônico podemos encontrar facilmente o Estatuto do partido na parte inferior da página inicial. A página https://www.psdb.org.br/conheca/codigo-de-etica não foi encontrada (Início>Página não encontrada).

Não foi encontrado um canal de denúncias propriamente dito, mas foi facilmente encontrado contatos da ouvidoria (ouvidoria@psdb.org.br / (61) 99633-8059), então assumisse que a denúncia poderia ser enviado a este e-mail ou telefone, apesar de que no sítio eletrônico somente anunciar dúvidas, críticas, informações e sugestões para a ouvidoria, mas não está claro o direcionamento.

\footnotetext{
${ }^{7}$ https://www.mdb.org.br/conheca/codigo-de-etica/

${ }^{8}$ RESOLUÇÃO-Nº-02-2020-CORONAVÍRUS.pdf.pdf (mdb.org.br)
} 
Foi encontrada a existência dos Conselhos de Ética e Disciplina nos artigos 53 a 55 do Estatuto, para a função de "apurar as infrações e violações à disciplina, à ética, à fidelidade e deveres partidários, emitindo parecer para decisão do Diretório correspondente.”. Conselho Fiscal previsto somente no artigo 56 do Estatuto.

\begin{tabular}{|c|c|c|r|r|}
\hline $\begin{array}{c}\text { REQUISI } \\
\text { TOS }\end{array}$ & $\begin{array}{r}\text { N } \\
\text { ão } \\
\text { atendeu } \\
\text { lmente, } \\
\text { porém não } \\
\text { satisfatório. }\end{array}$ & $\begin{array}{r}\text { Parcial } \\
\text { mente, porém } \\
\text { satisfatório }\end{array}$ & $\begin{array}{r}\text { Integra } \\
\text { lmente }\end{array}$ \\
\hline Suporte & & & $\mathrm{X}$ & \\
\hline $\begin{array}{c}\text { Canal de } \\
\text { denúncias }\end{array}$ & & & $\mathrm{X}$ & \\
\hline $\begin{array}{c}\text { Estrutura } \\
\text { interna }\end{array}$ & & $\mathrm{X}$ & & \\
\hline $\begin{array}{c}\text { Prestação } \\
\text { de contas }\end{array}$ & $\mathrm{X}$ & & & \\
\hline
\end{tabular}

\subsection{Republicanos - REPUBLICANOS}

Bancada de 32 deputados(as).

Bancada de 1 senador.

Endereço eletrônico: https://republicanos10.org.br/

No endereço eletrônico podemos encontrar o link para o Estatuto tanto na parte superior da página inicial quanto pode ser encontrado mais facilmente na parte inferior da página.

Para o segundo critério na página inicial do sítio eletrônico não se encontra o acesso ao canal de denúncias, apesar de ter um "Fale Conosco".

Não há acesso do Estatuto, pois segundo o novo Estatuto de 2019 aguarda homologação do TSE. Resoluções são facilmente encontradas, porém não se observou nenhuma estrutura de compliance dentro do partido.

Para o último criterio, se observa a iniciativa de trazer o perfil "Presidente do Conselho de Ética do Republicanos" na seguinte página: https://republicanos 10.org.br/quem_e quem/vinicius-carvalho-3/, bem como um página exclusiva para a Tesouraria (https://republicanos10.org.br/tesouraria/) do partido e o perfil do tesoureiro, mas não foi encontrada nenhuma prestação de contas. No final da página possui um "FALE COM A TESOURARIA“.

\begin{tabular}{|c|c|c|c|c|}
\hline $\begin{array}{c}\text { REQUISI } \\
\text { TOS }\end{array}$ & $\begin{array}{c}\text { ão } \\
\text { atendeu }\end{array}$ & $\begin{array}{r}\text { Parcial } \\
\text { mente, porém } \\
\text { não } \\
\text { satisfatório. }\end{array}$ & $\begin{array}{r}\text { Parcial } \\
\text { mente, porém } \\
\text { satisfatório }\end{array}$ & $\begin{array}{c}\text { Integra } \\
\text { lmente }\end{array}$ \\
\hline Suporte & & & $\mathrm{X}$ & \\
\hline $\begin{array}{c}\text { Canal de } \\
\text { denúncias }\end{array}$ & & $\mathrm{X}$ & & \\
\hline
\end{tabular}




\begin{tabular}{|c|c|c|l|l|}
\hline $\begin{array}{c}\text { Estrutura } \\
\text { interna }\end{array}$ & & $\mathrm{X}$ & & \\
\hline $\begin{array}{c}\text { Prestação } \\
\text { de contas }\end{array}$ & & $\mathrm{X}$ & & \\
\hline
\end{tabular}

\subsection{Bloco PROS, PSC, PTB}

Bancada com 33 deputados(as).

O PROS tem representação no Senado Federal com 3 senadores(as) e PSC com 1 senador.

\subsubsection{Partido Republicano da Ordem Social - PROS}

Endereço eletrônico: https://pros.org.br/

O Estatuto e o Código de Ética e Conduta foram facilmente encontrados.

\begin{tabular}{|c|r|r|r|r|}
\hline $\begin{array}{c}\text { REQUISI } \\
\text { TOS }\end{array}$ & $\begin{array}{r}\text { Nao } \\
\text { atendeu }\end{array}$ & $\begin{array}{c}\text { Parcial } \\
\text { mente, porém } \\
\text { não } \\
\text { satisfatório. }\end{array}$ & $\begin{array}{r}\text { Parcial } \\
\text { mente, porém } \\
\text { satisfatório }\end{array}$ & $\begin{array}{c}\text { Integra } \\
\text { lmente }\end{array}$ \\
\hline Suporte & & & & \\
\hline $\begin{array}{c}\text { Canal de } \\
\text { denúncias }\end{array}$ & $\mathrm{X}$ & & & \\
\hline $\begin{array}{c}\text { Estrutura } \\
\text { interna }\end{array}$ & & $\mathrm{X}$ & & \\
\hline $\begin{array}{c}\text { Prestação } \\
\text { de contas }\end{array}$ & $\mathrm{X}$ & & & \\
\hline
\end{tabular}

\subsubsection{Partido Social Cristão - PSC}

Endereço eletrônico: https://psc.org.br/

Não foi encontrado o Estatuto, Código de Ética e Conduta, Resoluções, Canal de denúncias ou qualquer estrutura de compliance.

Não atende aos critérios estipulados.

\begin{tabular}{|c|r|r|r|r|}
\hline $\begin{array}{c}\text { REQUISI } \\
\text { TOS }\end{array}$ & $\begin{array}{c}\text { ão } \\
\text { atendeu }\end{array}$ & $\begin{array}{c}\text { Parcial } \\
\text { mente, porém } \\
\text { não } \\
\text { satisfatório. }\end{array}$ & $\begin{array}{c}\text { Parcia } \\
\text { lmente, } \\
\text { porém } \\
\text { satisfatório }\end{array}$ & $\begin{array}{c}\text { Integra } \\
\text { lmente }\end{array}$ \\
\hline Suporte & $\mathrm{X}$ & & & \\
\hline $\begin{array}{c}\text { Canal de } \\
\text { denúncias }\end{array}$ & $\mathrm{X}$ & & & \\
\hline
\end{tabular}




\begin{tabular}{|c|r|l|l|l|}
\hline $\begin{array}{c}\text { Estrutura } \\
\text { interna }\end{array}$ & $\mathrm{X}$ & & & \\
\hline $\begin{array}{c}\text { Prestação } \\
\text { de contas }\end{array}$ & $\mathrm{X}$ & & & \\
\hline
\end{tabular}

\subsubsection{Partido Trabalhista Brasileiro - PTB}

Endereço eletrônico: https://ptb.org.br/

O Estatuto foi facilmente encontrado. O código de conduta não foi encontrado.

No último requisito se observa a Resolução PTB/CEN n. ${ }^{\circ} 88 / 2020^{9}$, no qual distribui os recursos financeiros recebidos pelo partido por meio do Fundo Especial de Financiamento de Campanha-FEFC.

\begin{tabular}{|c|c|c|c|c|}
\hline $\begin{array}{c}\text { REQUISI } \\
\text { TOS }\end{array}$ & $\begin{array}{c}\text { N } \\
\text { atondeu } \\
\text { mente, porém } \\
\text { não } \\
\text { satisfatório. }\end{array}$ & $\begin{array}{r}\text { Parcial } \\
\text { mente, porém } \\
\text { satisfatório }\end{array}$ & $\begin{array}{r}\text { Integra } \\
\text { lmente }\end{array}$ \\
\hline Suporte & & & $\mathrm{X}$ & \\
\hline $\begin{array}{c}\text { Canal de } \\
\text { denúncias }\end{array}$ & $\mathrm{X}$ & $\mathrm{X}$ & & \\
\hline $\begin{array}{c}\text { Estrutura } \\
\text { interna }\end{array}$ & & $\mathrm{X}$ & & \\
\hline $\begin{array}{c}\text { Prestação } \\
\text { de contas }\end{array}$ & & & & \\
\hline
\end{tabular}

\subsection{Partido Socialista Brasileiro - PSB}

Bancada com 31 deputados(as).

Endereço eletrônico: https://www.psb40.org.br/

No sítio eletrônico não se observa o Estatuto ou Código de Conduta.

Há no requisito da estrutura interna a existência do "Conselho de Ética e Fidelidade Partidária" (endereço: https://www.psb40.org.br/quem-somos/conselho-de-etica/ ) e de Conselho Fiscal (enereço: https://www.psb40.org.br/quem-somos/conselho-fiscal/), porém a simples existência não quer dizer eficiência ou eficácia.

\begin{tabular}{|c|r|c|c|c|}
\hline REQUISI & $\begin{array}{c}\text { NoS } \\
\text { atendeu }\end{array}$ & $\begin{array}{c}\text { Parcial } \\
\text { mente, porém } \\
\text { não } \\
\text { satisfatório. }\end{array}$ & $\begin{array}{r}\text { Parcial } \\
\text { mente, porém } \\
\text { satisfatório }\end{array}$ & $\begin{array}{c}\text { Integr } \\
\text { almente }\end{array}$ \\
\hline Suporte & $\mathrm{X}$ & & & \\
\hline
\end{tabular}

\footnotetext{
${ }^{9}$ https://ptb.org.br/resolucao-ptb-cen-no-88-2020/
} 


\begin{tabular}{|c|c|c|c|c|}
\hline $\begin{array}{c}\text { Canal de } \\
\text { denúncias }\end{array}$ & & $\mathrm{X}$ & & \\
\hline $\begin{array}{c}\text { Estrutura } \\
\text { interna }\end{array}$ & & $\mathrm{X}$ & & \\
\hline $\begin{array}{c}\text { Prestação } \\
\text { de contas }\end{array}$ & & $\mathrm{X}$ & & \\
\hline
\end{tabular}

\subsection{Democratas - DEM}

Bancada com 31 deputados(as).

Bancada com 6 senadores(as).

Endereço eletrônico: https://dem.org.br/

Estatuto facilmente encontrado na página inicial. $\mathrm{O}$ artigo 83 cita a existência de um "Código de Ética", porém o documento não é acessível.

O Conselho Fiscal é encontrado somente no artigo 82, enquanto o "Conselho de Ética Partidária" é encontrado no artigo 84.

Como noticiado pela mídia em geral, o referido partido junto ao partido PARTIDO SOCIAL LIBERAL - PSL planejam uma fusão, então a referida análise poderá sofrer mudança.

\begin{tabular}{|c|r|r|r|r|}
\hline $\begin{array}{c}\text { REQUISI } \\
\text { TOS }\end{array}$ & $\begin{array}{r}\text { N } \\
\text { ato } \\
\text { atendeu }\end{array}$ & $\begin{array}{r}\text { Parcia } \\
\text { lmente, } \\
\text { porém não } \\
\text { satisfatório. }\end{array}$ & $\begin{array}{r}\text { Parcial } \\
\text { mente, porém } \\
\text { satisfatório }\end{array}$ & $\begin{array}{c}\text { Integr } \\
\text { almente }\end{array}$ \\
\hline Suporte & & & $\mathrm{X}$ & \\
\hline $\begin{array}{c}\text { Canal de } \\
\text { denúncias }\end{array}$ & $\mathrm{X}$ & & & \\
\hline $\begin{array}{c}\text { Estrutura } \\
\text { interna }\end{array}$ & & $\mathrm{X}$ & & \\
\hline $\begin{array}{c}\text { Prestação } \\
\text { de contas }\end{array}$ & $\mathrm{X}$ & & & \\
\hline
\end{tabular}

\subsection{Partido Democrático Trabalhista - PDT}

Bancada com 25 deputados(as).

Bancada com 3 senadores.

Endereço eletrônico: https://www.pdt.org.br/

No canal de denúncias se observa no endereço eletrônico o contato pelo WhatsApp com o Diretório Nacional e no final da página de forma discreta o "Contato" com o partido. Todavia, permanece a falta de endereçamento da denúncia.

\begin{tabular}{|c|r|r|r|r|}
\hline $\begin{array}{c}\text { REQUISI } \\
\text { TOS }\end{array}$ & ão & $\begin{array}{c}\text { Parcia } \\
\text { lmente, }\end{array}$ & $\begin{array}{r}\text { Parcial } \\
\text { mente, porém }\end{array}$ & Integra \\
\hline
\end{tabular}




\begin{tabular}{|c|c|c|c|c|}
\hline & atendeu & $\begin{array}{c}\text { porém não } \\
\text { satisfatório. }\end{array}$ & satisfatório & lmente \\
\hline Suporte & & $\mathrm{X}$ & & \\
\hline $\begin{array}{c}\text { Canal de } \\
\text { denúncias }\end{array}$ & & $\mathrm{X}$ & & \\
\hline $\begin{array}{c}\text { Estrutura } \\
\text { interna }\end{array}$ & $\mathrm{X}$ & & \\
\hline $\begin{array}{c}\text { Prestação } \\
\text { de contas }\end{array}$ & & & & \\
\hline
\end{tabular}

\subsection{Solidariedade - SOLIDARIEDADE}

Bancada com 14 deputados(as).

Endereço eletrônico: https://www.solidariedade.org.br/

O Estatuto não se encontra na página inicial do endereço eletrônico, mas é acessível. Não tem o Código de Ética e Conduta, porém o Programa Partidário está na mesma situação do Estatuto, ou seja, não se encontra na página inicial do endereço eletrônico, mas é acessível.

Na página inicial tem um Fale Conosco na parte superior.

A Comissão de Ética Partidária é um órgão decisório (art. 75, I) e um órgão da direção nacional (art. 76). Conforme o artigo 91 do Estatuto o Conselho Fiscal tem a competência de examinar e dar parecer sobre a contabilidade do Partido, fiscalizar a execução do orçamento anual, além de supervisionar e acompanhar as atividades financeiras do Partido.

\begin{tabular}{|c|c|c|r|r|}
\hline $\begin{array}{c}\text { REQUISI } \\
\text { TOS }\end{array}$ & $\begin{array}{r}\text { ão } \\
\text { atendeu }\end{array}$ & $\begin{array}{r}\text { Parcia } \\
\text { lmente, } \\
\text { porém não } \\
\text { satisfatório. }\end{array}$ & $\begin{array}{r}\text { Parcial } \\
\text { mente, porém } \\
\text { satisfatório }\end{array}$ & $\begin{array}{r}\text { Integr } \\
\text { almente }\end{array}$ \\
\hline Suporte & & $\mathrm{X}$ & & \\
\hline $\begin{array}{c}\text { Canal de } \\
\text { denúncias }\end{array}$ & & $\mathrm{X}$ & & \\
\hline $\begin{array}{c}\text { Estrutura } \\
\text { interna }\end{array}$ & & $\mathrm{X}$ & \\
\hline $\begin{array}{c}\text { Prestação } \\
\text { de contas }\end{array}$ & $\mathrm{X}$ & & & \\
\hline
\end{tabular}

\subsection{Podemos - PODE}

Bancada com 10 deputados(as).

Bancada com 9 senadores.

Endereço eletrônico: https://www.podemos.org.br/ 
O Estatuto é facilmente encontrado. Não tem Código de Ética e Conduta, porém o Manifesto é facilmente encontrado.

Conforme o Estatuto se observa a existência do Conselho de Ética Partidária (arts. 51 a 53) e do Conselho Fiscal (arts. 49 e 50).

Pela notícia veiculada "Podemos realiza treinamento de dirigentes para divulgar as bases do seu inovador Programa de Compliance e Integridade. 12 de agosto de $2021^{10 ، ~ e ́ ~}$ mencionado na referida notícia a existência do Diretor Nacional de Compliance e Integridade, contudo, conforme a notícia os treinamentos dos dirigentes são somente no âmbito da administração nacional do partido e não se observa em ato normativo ou no Estatuto tal estrutura.

Se observa o canal de denúncia no seguinte link: https://transparencia.podemos.org.br/canal-de-denuncia/, no entanto, não é facilmente encontrado.

No último requisito destaca-se a transparência do partido na prestação de contas (https://transparencia.podemos.org.br/prestacao-de-contas/). Destaca-se de forma bastante positiva a iniciativa do partido nesse sentido.

\begin{tabular}{|c|c|c|r|c|}
\hline $\begin{array}{c}\text { REQUISI } \\
\text { TOS }\end{array}$ & $\begin{array}{r}\mathrm{N} \\
\text { ato } \\
\text { atendeu }\end{array}$ & $\begin{array}{r}\text { Parcia } \\
\text { lmente, } \\
\text { porém não } \\
\text { satisfatório. }\end{array}$ & $\begin{array}{r}\text { Parcial } \\
\text { mente, porém } \\
\text { satisfatório }\end{array}$ & $\begin{array}{c}\text { Integr } \\
\text { almente }\end{array}$ \\
\hline Suporte & & & $\mathrm{X}$ & \\
\hline $\begin{array}{c}\text { Canal de } \\
\text { denúncias }\end{array}$ & & & $\mathrm{X}$ & \\
\hline $\begin{array}{c}\text { Estrutura } \\
\text { interna }\end{array}$ & & & & $\mathrm{X}$ \\
\hline $\begin{array}{c}\text { Prestação } \\
\text { de contas }\end{array}$ & & & & \\
\hline
\end{tabular}

\subsection{Partido Socialismo e Liberdade - PSOL}

Bancada com 9 deputados(as).

Endereço eletrônico: https://psol50.org.br/

O Estatuto é facilmente encontrado. Não tem Código de Ética e Conduta, porém o Programa (partidário) é facilmente encontrado.

No critério do canal de denúncias foi encontrado o contato da Comissão Nacional de Ética (Contato: etica@ psol50.org.br), também foi observado um Fale com o PSOL, todavia em ambos os casos ainda permanece vago para onde direcionar a denúncia.

A Comissão de Ética encontra- se nos artigos 90 a 92. Não foi encontrado no Estatuto o Conselho Fiscal, mas se verifica a existência de conselheiros ${ }^{11}$.

\footnotetext{
${ }^{10}$ https://transparencia.podemos.org.br/noticias/podemos-realiza-treinamento-de-dirigentes-para-divulgar-asbases-do-seu-inovador-programa-de-compliance-e-integridade/

${ }^{11} \mathrm{https} / / / \mathrm{psol} 50$. org.br/partido/conselho-fiscal/
} 


\begin{tabular}{|c|c|c|r|r|}
\hline $\begin{array}{c}\text { REQUISI } \\
\text { TOS }\end{array}$ & $\begin{array}{r}\text { ão } \\
\text { atendeu }\end{array}$ & $\begin{array}{r}\text { Parcia } \\
\text { lmente, } \\
\text { porém não } \\
\text { satisfatório. }\end{array}$ & $\begin{array}{r}\text { Parcial } \\
\text { mente, porém } \\
\text { satisfatório }\end{array}$ & $\begin{array}{c}\text { Integr } \\
\text { almente }\end{array}$ \\
\hline Suporte & & & $\mathrm{X}$ & \\
\hline $\begin{array}{c}\text { Canal de } \\
\text { denúncias }\end{array}$ & & $\mathrm{X}$ & & \\
\hline $\begin{array}{c}\text { Estrutura } \\
\text { interna }\end{array}$ & & $\mathrm{X}$ & & \\
\hline $\begin{array}{c}\text { Prestação } \\
\text { de contas }\end{array}$ & $\mathrm{X}$ & & & \\
\hline
\end{tabular}

\subsection{Partido Novo - NOVO}

Bancada com 8 deputados(as).

Endereço eletrônico: https://novo.org.br/

O Estatuto e o Código de Ética e Conduta são encontrados, porém não na página inicial.

A Comissão de Ética Partidária foi encontrada no artigo 69 a 72 do Estatuto. Não foi observado no Estatuto a existência do Conselho Fiscal. sentido.

No último requisito destaca-se de forma bastante positiva a iniciativa do partido nesse

\begin{tabular}{|c|r|r|r|r|}
\hline $\begin{array}{c}\text { REQUISI } \\
\text { TOS }\end{array}$ & $\begin{array}{r}\mathrm{N} \\
\text { ato } \\
\text { atendeu }\end{array}$ & $\begin{array}{r}\text { Parcia } \\
\text { lmente, } \\
\text { porém não } \\
\text { satisfatório. }\end{array}$ & $\begin{array}{r}\text { Parcial } \\
\text { mente, porém } \\
\text { satisfatório }\end{array}$ & $\begin{array}{c}\text { Integr } \\
\text { almente }\end{array}$ \\
\hline Suporte & $\mathrm{X}$ & & & $\mathrm{X}$ \\
\hline $\begin{array}{c}\text { Canal de } \\
\text { denúncias }\end{array}$ & & $\mathrm{X}$ & & \\
\hline $\begin{array}{c}\text { Estrutura } \\
\text { interna }\end{array}$ & & & & $\mathrm{X}$ \\
\hline $\begin{array}{c}\text { Prestação } \\
\text { de contas }\end{array}$ & & & & \\
\hline
\end{tabular}

\subsection{Avante - AVANTE}

Bancada com 8 deputados(as).

Endereço eletrônica: https://avante70.org.br/

O Estatuto é facilmente encontrado. Não tem Código de Ética e Conduta. Foi encontrado um Manifesto. No canal de denúncias foi encontrado um contato com o partido. 
Se observa no Estatuto nos artigos 52 e 53 - Dos Conselhos de Ética e Disciplina; e no artigo 54 - Conselho Fiscal.

\begin{tabular}{|c|c|c|r|r|}
\hline $\begin{array}{c}\text { REQUISI } \\
\text { TOS }\end{array}$ & $\begin{array}{r}\mathrm{N} \\
\text { ão } \\
\text { atendeu }\end{array}$ & $\begin{array}{r}\text { Parcia } \\
\text { lmente, } \\
\text { porém não } \\
\text { satisfatório. }\end{array}$ & $\begin{array}{r}\text { Parcial } \\
\text { mente, porém } \\
\text { satisfatório }\end{array}$ & $\begin{array}{c}\text { Integr } \\
\text { almente }\end{array}$ \\
\hline Suporte & & $\mathrm{X}$ & & \\
\hline $\begin{array}{c}\text { Canal de } \\
\text { denúncias }\end{array}$ & & $\mathrm{X}$ & & \\
\hline $\begin{array}{c}\text { Estrutura } \\
\text { interna }\end{array}$ & & $\mathrm{X}$ & \\
\hline $\begin{array}{c}\text { Prestação } \\
\text { de contas }\end{array}$ & $\mathrm{X}$ & & & \\
\hline
\end{tabular}

\subsection{Partido Comunista do Brasil - PcdoB}

Bancada com 8 deputados(as).

Endereço eletrônico: https://pcdob.org.br/

O Estatuto é facilmente encontrado. Não tem Código de Ética e Conduta, porém há um Programa partidário. No canal de denúncias foi encontrado um contato com o partido.

$\mathrm{Na}$ estrutura interna foi encontrado às Comissões de Controle no artigo 48 do Estatuto. Obrigatório no âmbito federal e estadual e recomendável no âmbito municipal.

\begin{tabular}{|c|c|c|r|c|}
\hline $\begin{array}{c}\text { REQUISI } \\
\text { TOS }\end{array}$ & $\begin{array}{r}\text { ão } \\
\text { atendeu }\end{array}$ & $\begin{array}{r}\text { Parcia } \\
\text { lmente, } \\
\text { porém não } \\
\text { satisfatório. }\end{array}$ & $\begin{array}{r}\text { Parcial } \\
\text { mente, porém } \\
\text { satisfatório }\end{array}$ & $\begin{array}{c}\text { Integr } \\
\text { almente }\end{array}$ \\
\hline Suporte & & $\mathrm{X}$ & & \\
\hline $\begin{array}{c}\text { Canal de } \\
\text { denúncias }\end{array}$ & & $\mathrm{X}$ & & \\
\hline $\begin{array}{c}\text { Estrutura } \\
\text { interna }\end{array}$ & & $\mathrm{X}$ & & \\
\hline $\begin{array}{c}\text { Prestação } \\
\text { de contas }\end{array}$ & $\mathrm{X}$ & & & \\
\hline
\end{tabular}

\subsection{Cidadania - CIDADANIA}

Bancada com 7 deputados(as).

Bancada com 3 senadores(as).

Endereço eletrônica: https://cidadania23.org.br/ 
$\mathrm{Na}$ abertura do endereço eletrônico aparece um pop up sobre a política de cookies conforme a LGPD, mostra o interesse do partido em estar em conformidade com a legislação de proteção de dados.

O Estatuto e Código de Ética e Conduta são facilmente encontrados.

Foi encontrado no final da página um contato com o partido (contato@ cidadania23.org.br), mas permanece a dúvida de onde encaminhar a denúncia.

Há a existência do Conselho de Ética e do Conselho Fiscal, não foi observado nenhuma outra estrutura interna de compliance.

\begin{tabular}{|c|c|c|r|r|}
\hline $\begin{array}{c}\text { REQUISI } \\
\text { TOS }\end{array}$ & $\begin{array}{r}\text { ão } \\
\text { atendeu } \\
\text { lmente, } \\
\text { porém não } \\
\text { satisfatório. }\end{array}$ & $\begin{array}{r}\text { Parcia } \\
\text { mente, porém } \\
\text { satisfatório }\end{array}$ & $\begin{array}{r}\text { Integr } \\
\text { almente }\end{array}$ \\
\hline Suporte & & $\mathrm{X}$ & & \\
\hline $\begin{array}{c}\text { Canal de } \\
\text { denúncias }\end{array}$ & & $\mathrm{X}$ & & \\
\hline $\begin{array}{c}\text { Estrutura } \\
\text { interna }\end{array}$ & & $\mathrm{X}$ & & \\
\hline $\begin{array}{c}\text { Prestação } \\
\text { de contas }\end{array}$ & $\mathrm{X}$ & & & \\
\hline
\end{tabular}

\subsection{Patriota - PATRIOTA}

Bancada com 6 deputados(as).

Bancada com 1 senador.

Endereço eletrônico: https://patriota51.org.br/

O Estatuto foi facilmente encontrado.

Foi encontrado somente um contato com o partido.

O Conselho de Ética do PATRIOTA é um órgão nacional (artigo 29, inciso VII, do Estatuto) e é encontrado nos artigos 41 e 42 do Estatuto. O Conselho Fiscal é encontrado no artigo 39 e 40. A competência do tesoureiro está no artigo 37, §§8 e 9, do Estatuto. Não foi encontrada qualquer outra estrutura interna de compliance.

\begin{tabular}{|c|c|c|c|c|}
\hline $\begin{array}{c}\text { REQUISI } \\
\text { TOS }\end{array}$ & $\begin{array}{r}\mathrm{N} \\
\text { ão } \\
\text { atendeu }\end{array}$ & $\begin{array}{r}\text { Parcia } \\
\text { lmente, } \\
\text { porém não } \\
\text { satisfatório. }\end{array}$ & $\begin{array}{r}\text { Parcial } \\
\text { mente, porém } \\
\text { satisfatório }\end{array}$ & $\begin{array}{c}\text { Integr } \\
\text { almente }\end{array}$ \\
\hline Suporte & & $\mathrm{X}$ & & \\
\hline $\begin{array}{c}\text { Canal de } \\
\text { denúncias }\end{array}$ & & $\mathrm{X}$ & & \\
\hline Estrutura & & & & \\
\hline
\end{tabular}




\begin{tabular}{|c|r|l|l|l|}
\hline interna & & & & \\
\hline $\begin{array}{c}\text { Prestação } \\
\text { de contas }\end{array}$ & $\mathrm{X}$ & & & \\
\hline
\end{tabular}

\subsection{Partido Verde - PV}

Bancada de 4 deputados(as).

Endereço eletrônico: https://pv.org.br/

Estatuto facilmente encontrado. Código de Ética e Conduta não encontrado, porém se observa a declaração dos no documento "Princípios e Valores", bem como no Manifesto do partido.

Existe o contato com o partido (nacional.pv@gmail.com), porém permanece a dúvida do endereçamento da denúncia. No artigo 27, inciso II, do Estatuto foi constatada a existência de uma ouvidoria como órgão de apoio e cooperação, porém inacessível.

No entanto, no artigo 78 do Estatuto, além de direcionar as reclamações (artigo 79, III) a ouvidoria é um órgão mediador de conflitos.

\begin{tabular}{|c|c|c|r|l|}
\hline $\begin{array}{c}\text { REQUISI } \\
\text { TOS }\end{array}$ & $\begin{array}{r}\text { ão } \\
\text { atendeu }\end{array}$ & $\begin{array}{r}\text { Parcia } \\
\text { lmente, } \\
\text { porém não } \\
\text { satisfatório. }\end{array}$ & $\begin{array}{r}\text { Parcial } \\
\text { mente, porém } \\
\text { satisfatório }\end{array}$ & $\begin{array}{r}\text { Integr } \\
\text { almente }\end{array}$ \\
\hline Suporte & & $\mathrm{X}$ & & \\
\hline $\begin{array}{c}\text { Canal de } \\
\text { denúncias }\end{array}$ & & $\mathrm{X}$ & & \\
\hline $\begin{array}{c}\text { Estrutura } \\
\text { interna }\end{array}$ & & $\mathrm{X}$ & & \\
\hline $\begin{array}{c}\text { Prestação } \\
\text { de contas }\end{array}$ & $\mathrm{X}$ & & & \\
\hline
\end{tabular}

\subsection{Partido Sustentabilidade - SUSTENTABILIDADE}

Bancada de 4 deputados(as).

Bancada com 2 senadores

Endereço eletrônico: http://redesustentabilidade.org.br/

O Estatuto é facilmente encontrado. Não tem Código de Ética e Conduta. Foi encontrado um Manifesto. No canal de denúncias foi encontrado contatos com o partido no final da página.

\begin{tabular}{|c|c|c|c|c|}
\hline REQUISITOS & $\begin{array}{c}\text { Não } \\
\text { atendeu }\end{array}$ & $\begin{array}{c}\text { Parcialmente, } \\
\text { porém não } \\
\text { satisfatório. }\end{array}$ & $\begin{array}{c}\text { Parcialmente, } \\
\text { porém } \\
\text { satisfatório }\end{array}$ & Integralmente \\
\hline Suporte & & & $\mathrm{X}$ & \\
\hline
\end{tabular}




\begin{tabular}{|c|c|c|l|l|}
\hline $\begin{array}{c}\text { Canal de } \\
\text { denúncias }\end{array}$ & & $X$ & & \\
\hline Estrutura interna & & $X$ & & \\
\hline $\begin{array}{c}\text { Prestação de } \\
\text { contas }\end{array}$ & $X$ & & & \\
\hline
\end{tabular}

\section{RESULTADOS E CONCLUSÕES}

Dentre os partidos analisados somente o PSL, MDB, NOVO, PROS e CIDADANIA alcançaram o requisito "Integralmente" no critério "Suporte", onde no qual se observa a existência do Estatuto e o Código de Ética e Conduta conjuntamente.

Quanto ao critério "Canal de Denúncia", os partidos, em geral, estão aquém do satisfatório, porém destaca-se a existência de ouvidorias no PSL e PSDB. O PT apesar da existência de uma ouvidoria no Estatuto não pôde ser encontrado na página inicial.

Destaca-se o PSL pela existência de uma estrutura interna de compliance observável na Resolução Interna CEN 003/2020, o que não se vislumbra nos outros partidos analisados. Contudo, apesar de não ser demonstrável em ato normativo do partido o PODE se destaca também no presente requisito.

No último requisito destaca-se o PODE e o NOVO como os únicos partidos a atender o requisito "Integralmente" no critério de "Prestação de contas", sem contudo, vale destacar a iniciativa pela divulgação dos requisitos de distribuição do Fundo Especial de Financiamento de Campanha - FEFC pelo:

i) PTB através da Resolução PTB/CEN n. ${ }^{\circ} 88 / 2020$;

ii) PSB através da Resolução CEN 004/202012;

iii) PDT através da Resolução 003/202013; e

iv) PODE através das Resoluções Nacionais n. ${ }^{\circ}$ s 02 e 03 de 2020.

Porém, perante a boa iniciativa dos referidos partidos, a maioria ainda precisa considerar a transparência das contas partidárias. Neste mesmo critério os partidos analisados foram em sua imensa maioria pífios em alcançar qualquer ponto no sentido de transparência das contas, apesar da existência dos Conselhos Fiscais em seus Estatutos.

Apesar da existência de Conselhos de ética ou com nomenclatura equivalente, haja vista a análise somente documental não se observa a eficácia de tais conselhos, contudo pelas notícias veiculadas pela mídia em geral, pontuais e aleatórios, principalmente pelas "páginas policiais", não traz nenhuma notícia satisfatória dos partidos e por consequência de tais órgãos partidários na fiscalização da ética e da integridade do partido, podemos deduzir que a eficácia de tais órgãos não atinge um critério razoavelmente bom.

Ao contrário da percepção geral e apriorística da população sobre os partidos políticos brasileiros, se observa pontualmente iniciativas positivas e interessantes já mencionadas e analisadas individualmente, assim, como se observa, o partido NOVO foi o único partido analisado a conseguir o requisito "Integralmente", tanto no critério "Suporte" quanto no critério "Prestação de contas".

\footnotetext{
12 https://www.psb40.org.br/cms/wp-content/uploads/2020/09/Resolu\%C3\%A7\%C3\%A3o-CEN-004-FundoEleitoral-1.pdf

${ }^{13}$ https://www.pdt.org.br/wp-content/uploads/2020/08/Resolucao_003-2020-FEFC.pdf
} 
Ressalta-se que a análise dos partidos é simplesmente documental e por consequência não é possível a verificação da cultura de integridade (partidária) na prática, assim, a partir dos resultados, de maneira geral, destaca-se de forma positiva os partidos PSL, PODE e o NOVO, do outro lado o PL e o PSC se destacam de forma negativa em razão de não observar nenhum critério analisado.

Nos demais partidos não se observa grandes destaques a partir dos critérios analisados, mas se observa algumas iniciativas simples e interessantes dos partidos que valem a atenção, como por exemplo o PDT e o PT disponibilizam um App aos filiados; o CIDADANIA ao entrar em seu endereço eletrônico pergunta o consentimento de utilização de cookies conforme a Lei Geral de Proteção de Dados; o PODE tem uma página exclusiva sobre a transparência.

Apesar de não ser o ideal, seria interessante, no mínimo, para os partidos disponibilizarem links para a Justiça Eleitoral, ou melhor, para a figura do Tribunal Superior Eleitoral, principalmente para os pequenos partidos, nos quais tem menor representação e, portanto, poucos recursos.

A partir dos exemplos pontuais dos partidos "nanicos", podemos concluir que os partidos com maior representação não são necessariamente os melhores em transparência, por mais que se possa induzir do contrário - por terem mais recursos em tese, por outro lado não se pode concluir também que são os piores. Mas as "melhores práticas", paradoxalmente, se concentram em grande medida nos partidos ditos pequenos, que são conhecidos no imaginário político popular, normalmente, como partidos fisiológicos, vulgo "Centrão". No entanto, o sistema partidário, digo, partidos, seja com maior ou menor representação, precisa melhorar substancialmente a sua forma de condução da integridade/ética.

\section{REFERÊNCIAS}

BOBBIO, Norberto, 1909 - Dicionário De Política - Norberto Bobbio, Nicola Matteucci e Gianfranco Pasquino; trad. Carmen C., Varriale et ai.; coord. trad. João Ferreira; rev. geral João Ferreira e Luis Guerreiro Pinto Cacais. - Brasília: Editora Universidade de Brasília, $11^{\mathrm{a}}$ ed., 1998. Vol. 1 : 674p. (total: 1.330p.). Vários colaboradores. Obra em 2v.

Todos os links presentes neste artigo foram retirados e disponibilizados pelos próprios partidos nos seus respectivos endereços eletrônicos com acesso no mês de Agosto de 2021. 